\title{
What is it to do good medical ethics? Minding the gap(s)
}

\author{
Deborah Bowman
}

\section{Correspondence to}

Prof Deborah Bowman, Professor of Bioethics, Clinical Ethics and Medical Law, St. George's, University of London, London SW170RE, UK; dbowman@sgul.ac.uk

Received 24 August 2014 Revised 9 September 2014 Accepted 1 October 2014
CrossMark

To cite: Bowman D. J Med Ethics 2015;41:60-63.

\begin{abstract}
This paper discusses the character of medical ethics and suggests that there are significant gaps that warrant greater attention. It describes ways in which the content and form of medical ethics may exclude or marginalise perspectives and contributions, thereby reducing its influence and its potential impact on, and value to, patients, students, carers and society. To consider what it is 'to do good medical ethics' suggests an active approach that seeks out, and learns from, contributions beyond the traditional boundaries of scholarship.
\end{abstract}

\section{INTRODUCTION}

It is both liberating and daunting to have the opportunity to respond to such an open question. This is a paper that has taken rather longer to mature than I expected. Initially, the question - 'what is it to do good medical ethics'-prompted myriad ideas. Those early responses had an amorphous quality-momentarily glimpsed and occasionally tantalising in character, but more often frustratingly elusive and poorly articulated. I lived with these Will-o'-the-wisp notions of 'good medical ethics' for many months. In the half-light of early mornings, I jotted down thoughts and hoped they would, when the sun rose, distil into something more coherent. I began to amass papers, to return to classic texts and to interrogate what I do routinely. My pursuit of, and failure to find, my eureka moment is revealing about the nature of our subject: its conventions, its priorities, its norms and expectations. In this paper, I discuss the character of 'medical ethics' and suggest that while it is a rich area of inquiry, there are significant gaps that warrant greater attention. I propose that the use of the verb 'to do' in the title suggests a particular approach to medical ethics that requires acknowledgement of, and an active response to, those gaps beyond the traditional boundaries of academic scholarship.

\section{CONSTRUCTING MEDICAL ETHICS}

Medical ethics has developed according to the conventions of scholarly inquiry. That matters if a subject is to become established and respected. This journal has done much to enhance the scholarly reputation of medical ethics. We owe its founders and subsequent editors a great debt. However, some of the effects of the dominant method for discussing medical ethics are that the notion of good medical ethics is characterised by approaches ${ }^{1}$ that may limit other methods of engagement and exclude particular groups. The default interpretation of 'doing good medical ethics' reflects the academic model, usually beginning with an issue or a question and leading to a robust argument. Most commonly, discussions of medical ethics occur in academic writing or presentations. Others will read or listen and respond, usually adopting the accepted format. Counterarguments will be disseminated to a specialist, often small, audience. As someone who has made her career as an academic and edits a journal, ${ }^{2}$ I am on shaky ground in questioning this established format, but nonetheless I suggest that doing good medical ethics has to be more imaginative, inclusive and active.

The character of medical ethics reveals its priorities, preferences and assumptions. Its inquiries and methods do not happen by chance. It matters in consideration of what it is to 'do good medical ethics'. The determination of the question(s) we explore, and the ways in which we do so, are moral acts depending on power, status and privileging certain types of experience and knowledge. Consider the average young scholar. She will probably be encouraged or required to harness her interests and research to the priorities of her institution. Indeed, she may have been recruited with that contribution in mind. Her research is likely to be shaped by the work of her seniors-she may be standing on the shoulders of giants or she may be working with ogres. As her career develops, she may compete for external funding and have to adapt accordingly. Papers she writes will draw on, and respond to, the work that journals are publishing and conferences are accepting. She is likely to become more specialist encouraged by many who advise that she must aspire to being 'an expert' in a particular aspect of medical ethics. She may rarely leave her office (or, perhaps more realistically, her hot desk in the open plan area) and the opportunities for her to speak to anyone other academics about her ideas and interests may be negligible. Finally, she is, of course, a product of her own background, experience and disciplinary training. What she understands, and represents in papers, presentations and to students, as being good medical ethics is likely to fall within a narrow range, not because she lacks curiosity or is deliberately excluding other perspectives, but as a function of the system within which she hopes to progress.

Good medical ethics requires attention to its antecedents and the influences on the same. The joy of the subject is that it is interdisciplinary and scholars are drawn from a wide range of academic backgrounds. However, the field, in contrast to its scholars, is shaped by biomedicine and its progress. Medical ethics commonly focuses on the moral implications of biomedical development and innovation, often after the event. This may not be problematic. I would rather scholars noticed and 
attended to the realities and rhetoric of biomedical progress. Yet, it has implications for defining good medical ethics. Even when medical ethics examines the relational aspects of medicine and healthcare, it largely reflects the medical model and is concerned with what happens between doctor and patient in clinical settings rather than in the home, with carers, in schools, in residential homes, on internet message boards and online fora, at day centres or as part of community and advocacy groups.

Good medical ethics must be aware of, and engage with, its context. It must notice that which is dominating headlines and journals and that which is not. Otherwise, it may unwittingly replicate inequity, social exclusion and marginalisation. It should attend to the absences and the gaps. As Havi Carel has eloquently suggested, there are multiple ways in which epistemic injustice ${ }^{3}$ occurs within medicine and healthcare. ${ }^{4}$ It also occurs within medical ethics. To understand the ways in which perspectives are distorted and voices unheard or even silenced matters. It does not just reveal a richer landscape for inquiry, but is itself an ethical choice. And the word 'choice' matters. It implies an active commitment to exploring the way the 'medical ethics' is characterised. It demands attention to what knowledge, beliefs or perspectives are privileged and what is, often unintentionally but nonetheless significantly, overlooked, disregarded or ignored. It is fundamental to doing good medical ethics.

Consider, for example, the case or scenario in medical ethics, a common approach to medical ethics. ${ }^{5}$ There is a significant literature on how to use a case-based approach in clinical practice and learning, ${ }^{67}$ but comparatively little has been written about the construction of 'the case' itself and the power that resides in those who have the discretion to construct and present 'the case' or 'the story' or 'the problem'., ${ }^{8-10}$ Whatever the form, choices are made in even the simplest presentation of an 'ethical issue'. ${ }^{11}$ Interrogating those choices demands attention to, for example, presence and absence, voice and silence, naturalism and symbolism, text and subtext, form and meaning and authorial status and intent. ${ }^{12}$ Anyone who shares or reads a narrative, case or story about a health experience is engaged in complex moral work: choosing how to write, to communicate and to read $^{13}$ is integral to doing good medical ethics.

It is a non-academic experience that has been most instructive about the construction and representation of cases and stories in medical ethics. In 2003, a BBC producer contacted me. That discussion led to "Inside the Ethics Committee"14 for Radio 4. I have been a consultant to, and regular panellist for, each of its 10 series. It has taught me an enormous amount both in relation to how ethical issues are communicated and the value of engaging with an audience beyond the academic and professional. In 2004, I pitched up to the recording studio nervous but eager to convey my expertise and to share theories, landmark cases and seminal papers. I was kindly, but firmly, told that a simpler (note, not simplified) approach was required. Initially, I chafed against this instruction bemoaning the impossibility of doing justice to complex arguments. I was wrong. I learned to listen in ways that are not necessarily natural to academics keen to share their expertise. I heard stories in ways that were unfamiliar. People spoke to us from their homes, not in clinics, surgeries or hospitals. We heard, of course, from the professional involved in the case, but crucially we afforded equal or greater weight to the patient's testimony and that of family or carers. People shared their experiences and perspectives without mediation or well-meaning interpretation. What they said was often surprising, sometimes revelatory and always elucidating. It was not unusual for the professionals involved to hear information for the first time. As the series evolved, the panel expanded to include those who had experience of illness, caring or advocacy. Those programmes were, in my view, the best we made. Despite my initial anxieties about relinquishing my academic comfort blankets of theories, cases and papers, the discussions were always nuanced and rigorous. It was transformative and continues to inform my understanding of what it is to do good medical ethics.

\section{MODERATION AND MEANING IN MEDICAL ETHICS}

Another aspect of the dominant form in medical ethics that creates gaps is that of 'position'. Within medical ethics, the scholarly convention is to marshal robust arguments using reason and logic to reach a substantiated conclusion. It is a fine approach. The facility to argue coherently, to challenge other points of view and to reach well-considered conclusions is invaluable. And yet, however well it is done and irrespective of how much I admire a particular author or paper, it often leaves me dissatisfied. It is an approach that depends on distinction and divergence. It is a way of working that fosters opposition when healthcare is, in general, an uncertain and collaborative endeavour. Adopting and arguing for a position is considered integral, even essential, to good medical ethics. The alternative is often characterised as confused or weak. Yet, not taking a 'position' recognises false divides and allows for listening, dialogue and learning.

Most of my time and work is not spent with others who work in medical ethics, but involves students, clinicians, patients, carers, community groups and, that most curiously named category, 'the public'. I have sought, and increasingly been sought by, those beyond the University. I am not alone in believing that actively seeking other perspectives matters for many reasons, including accountability, transparency, equality, diversity and inclusion. ${ }^{15-17}$ In many of my interactions, oppositional argument-however articulate and persuasive-is rarely helpful. Shutting up, listening and reflecting are what matters. Those with whom we interact and the humility we bring to those contacts reflect a moral stance: one that recognises the gaps in the priorities, methods and outputs of contemporary medical ethics. It has prompted me to consider questions that would never otherwise have occurred to me, to reflect on arguments I have not encountered in the specialist academic literature, to recognise the contributions of people and organisations beyond the clinician and patient, and to see the field of 'medical ethics' through a different lens.

Many_professionals, students and 'the public' alike-come to medical ethics not only to understand the moral dimensions of medicine, but in the belief that it will speak to their experience of illness and its treatment. For some, it is so, but for many it is not. Take, for example, the subject of 'consent'. It is likely to feature in every curriculum. Most assessments will include consent. A search reveals hundreds of papers written about consent. I too have written ${ }^{18}$ and spoken about consent many times. And yet, students, clinicians, patients and carers describe ethical problems that continue irrespective of the depth of their knowledge or facility to debate consent. Students recount difficulties introducing themselves to patients because of a senior's discouragement. Carers describe how inadequately a relative has been involved in care planning. Clinicians relay the mismatch between working conditions and the possibility of facilitating meaningful choice. ${ }^{19}$ None of this is remedied by 'more medical ethics', at least in its conventional form.

For some, what I am describing may seem like the difference between academic medical ethics and clinical ethics. However, it is more fundamental than that somewhat arbitrary distinction. 
Moreover, even the most 'applied' questions encompass a theoretical claim, assumption or disposition. It is a function of gaps in our conceptualisation of medical ethics that risk it seeming inaccessible, misdirected or marginal. It is a consequence of a dominant approach that sits comfortably in the academic setting, but lacks resonance and meaning to many of those whom we might hope to engage. A paper may be beautifully argued, a conference presentation may prompt searching debate and a curriculum may provide outstanding teaching, but to what extent do those achievements relate to ethical questions that affect millions of people ${ }^{20}$ Of course, there is inherent value in traditional scholarship and its methods. The extent to which students, both undergraduate and postgraduate, can critique arguments, engage with debate and develop coherent conclusions remains a marker of attainment. Nonetheless, even the most academically able student will commonly describe that their engagement with ethics, while stimulating, is of limited value in navigating clinical training or practice. For some, perhaps, these perceived gaps may suggest a misguidedly instrumental notion of the subject, but good medical ethics dismisses these gaps at its peril.

\section{MIND THE GAP: PEOPLE, PROBLEMS AND PRIORITIES IN MEDICAL ETHICS}

Medical ethics has achieved much in developing the moral awareness of those who study it. Yet, for many, that learning is limited in its impact. ${ }^{21}$ To do good medical ethics is surely to be empowered to act. Yet, moral distress ${ }^{22} 23$ has been described in a range of settings., ${ }^{24-26}$ Like most people working in medical ethics, I welcomed the consensus statement ${ }^{27}$ on curriculum content and I have been proud to contribute to its evolution. ${ }^{28}$ Nonetheless, the comprehensive content does not reflect questions, priorities and concerns that commonly arise for students. Despite the best efforts of those involved in education, many students feel or are ethically compromised during their training., ${ }^{29-31}$ What's more, even when a student raises a question that falls squarely within 'core' curriculum content, it is rarely a matter of knowledge or facility with argument that is the concern. What is at issue, most commonly, is the vexed question of how to act well in a hierarchical and challenging healthcare system. It arises for students in the earliest days of their training and for professionals of many years' standing. And it is not just students and those in the health professions with whom we should be concerned. Those whose experiences are less frequently considered, such as relatives, carers, visitors, managers, healthcare assistants, volunteers and commissioners, also describe moral distress.

A core curriculum in medical ethics that prioritises analysis, reasoning and argument is necessary, but not sufficient to do good medical ethics. Ethical competence does not lead inexorably to ethical confidence (and vice versa). ${ }^{32}$ At my medical school, these gaps between the classroom and the clinic prompted the 'ethics road show': a student-led, small group session in which participants discuss their experiences. Recurrent themes include introductions, disclosure of student status, inappropriate instructions from seniors, humiliating interactions, disregard for dignity, responses to patient distress or pain and questions of honesty. Although these sessions have evolved, the central premise-that they are student-led and student-focusedremains. These are spaces where both analytic and reflective approaches are valued. Attention is given to the intellectual and the emotional response because both matter. ${ }^{33}$ As well as providing an opportunity to discuss experiences, these sessions also offer a safe rehearsal space to practise responses to difficult situations. Inspired by the work of Mary Gentile, ${ }^{34}$ students are invited to share and try out ways of responding in challenging interactions. Just as they practise their clinical skills, they practise learning how to speak out in a hierarchical system. The focus is on what it is to have ethical wisdom and moral courage. These are sessions where the emphasis is as much on 'doing' medical ethics as it is on discussing medical ethics.

\section{CONCLUSION}

There are, of course, many ways of doing good medical ethics. Good medical ethics is evident at conferences, in lecture theatres and in journals. However, there are gaps and omissions, attention to which has the potential to enrich the field fostering greater diversity and inclusivity and extending its influence. For me, actively seeking perspectives and contributions from people other than academics and clinicians has been invaluable and transformative. It has resulted in learning from, and collaboration with, carers, healthcare assistants, school children, people who are ill but challenge what it is 'to be a patient', performers, artists, students and broadcasters. This work has altered my conceptual and practical understanding of 'medical ethics'. It has shaped how I perceive the methods and preoccupations of what is commonly portrayed as good medical ethics. Most fundamentally, it has convinced me that how we represent and choose to 'do' medical ethics is itself of moral importance.

\section{Competing interests None.}

Provenance and peer review Commissioned; internally peer reviewed.

\section{REFERENCES}

1 Sulmasy DP. Reading the medical ethics literature: a discourse on method. In: Sugerman J, Sulmasy, DP, (eds). Methods in medical ethics. Washington, DC: Georgetown University Press, 2001:315-28.

2 Medical Humanities. London: BMJ. http://mh.bmj.com/.

3 Fricker M. Epistemic injustice: power and the ethics of knowing. Oxford: Clarendon Press, 2007.

4 Carel H. Illness. London: Routledge, 2008

5 Hurwitz B. Form and representation in clinical case reports. Lit Med 2006;25:216-40.

6 Molewijk AC, Abma T, Stolper M, et al. Teaching ethics in the clinic: the theory and practice of moral case deliberation. J Med Ethics 2008;34:120-4.

7 Malek J, Geller G, Sugerman J. Talking about cases in bioethics: the effect of an intensive course on healthcare professionals. J Med Ethics 2000;26:131-6.

8 Liaschenko J, Oguz NY, Brunquell D. Critique of the "tragic case" method in ethics education. J Med Ethics 2006:32:672-7.

9 Pattison D, Dickenson D, Parker $M$, et al. Do case studies mislead about the nature of reality? J Med Ethics 1999;25:42-6.

10 Chambers TS. The bioethicist as author: the medical ethics case as a rhetorical device. Lit Med 1994;13(1):60-78.

11 Hurwitz B. Textual practices in crafting bioethics cases. J Bioeth Inq 2012;4 (9):395-401.

12 Brody H. "My story is broken; can you help me fix it?": medical ethics and the joint construction of narrative. Lit Med 1994:31:79-92.

13 Woods A. Rethinking "patient testimony" in the medical humanities: the case of Schizophrenia Bulletin's first person accounts. J Lit Sci 2012;6(1):38-64

14 Eastwood B. Inside the Ethics Committee: bringing the ethical dilemmas of modern medicine to BBC Radio 4. Clin Ethics 2010;5:54-6.

15 Neitzke G. Patient involvement in clinical ethics services: From access to participation and membership. Clin Ethics 2009;4:146-51.

16 Newson A. The role of patients in clinical ethics support: a snapshot of practices and attitudes in the United Kingdom. Clin Ethics 2009;4:139-45.

17 Fournier $\mathrm{V}$, Rari $\mathrm{E}$, Forde $\mathrm{R}$, et al. Clinical ethics consultation in Europe: a comparative and ethical review of the role of patients. Clin Ethics 2009;4:131-8.

18 Bowman D, Spicer J, Iqbal R. Informed consent. Cambridge: Cambridge University Press, 2011.

19 Gallagher. A slow ethics: a sustainable approach to ethical care practices. Clin Ethics 2013;8(4):98-104

20 Keller F, Allert G, Baitsch $\mathrm{H}$, et al. Discourse ethics in practical medicine. Med Humanities 2006:32:99-103.

21 McDougall R. Combatting junior doctors' " 4 am logic": a challenge for medical ethics education. J Med Ethics 2009;35:203-6.

22 Wiggleton C, Petrusa E, Loomis K. Medical Students' experiences of moral distress: development of a web-based survey. Acad Med 2010;85(1):111-17.

23 Pauly BM, Varcoe C, Storch J. Framing the issues: Moral distress in healthcare. HEC Forum 2012;24:1-11. 
24 Cordingley L, Hyde C, Peters $\mathrm{S}$, et al. Undergraduate medical students' exposure to clinical ethics: a challenge to the development of professional behaviours? Med Educ 2007;41(12):1202-9.

25 Silverman HJ, Dagenais J, Gordon-Lipkin E, et al. Perceived comfort levels of medical students and residents in handling clinical ethics Issues. J Med Ethics 2013;39:55-8.

26 Malpas PJ. Reflecting on senior medical students' ethics reports at the University of Auckland. J Med Ethics 2011;37:627-30.

27 Donaldson TM, Fistein E, Dunn M. Teaching medical ethics and law within medical schools: a model for the UK core curriculum. J Med Ethics 1998;24:188-92.

28 Stirrat GM, Johnston C, Gillon R, et al. Teaching and learning ethics: medical ethics and law for doctors of tomorrow: the 1998 consensus statement updated. J Med Ethics 2010;36(1):55-60.
29 Price J, Price D, Williams G, et al. Changes in medical student attitudes as they progress through a medical course. J Med Ethics 1998;24:110-17.

30 Feudtner C, Christakis DA, Christakis, NA. Do clinical clerks suffer ethical erosion? Students' perceptions of their ethical environment and personal development. Acad Med 1994;69(8):670-9.

31 Satterwhite RC, Satterwhite WM, Enarson C. An ethical paradox: the effect of unethical conduct on medical students' values. J Med Ethics 2000;26: 462-5.

32 Bowman D. The challenges of an ethical education in Europe. Die Psychiatrie 2005;2(3):158-65.

33 Zucker A. Medical ethics as therapy. J Med Ethics 2006;32:48-52.

34 Gentile M. Giving voice to values. New Haven: Yale University Press. 